\title{
EDITORIAL
}

\section{Growth in Australian youth suicide}

Australian society has adapted to an increased frequency of youth suicide, parasuicide, depression, and dysfunctional social support systems. Closer inspection from the Australian Institute of Suicide Prevention and Research does not uphold our complacent view outwards to other societies or inwards to our own historical-cultural social ecology. Our own individual, professional, and academic social networks can reveal surprising habituation to suicide phenomena in our extended families, network of acquaintance, and neighbourhood. Any suicide event, taken individually, will elicit empathy with survivors and reflection about better supervision, support, or even awareness of indicators prior to a suicide. Cumulatively, however, the extent of suicidal behaviour and suicidal risk seems to be ignored, and suicide events are attributed to inexorable, unpredictable, and unpreventable effects of social change, economic hopelessness, and personal weakness.

Reversal of cross-cultural trends means that, as a nation, we cannot be critical and condemnatory of, for example, Japanese student suicide related to pressures to academic achievement and social conformity: Our own values and social system are associated with higher rates of juvenile suicide.

Government reports of health and education problems among young Aboriginal Australians extend over decades. Media coverage now regularly deals with issues such as deaths in custody, lost generation children, and glue-sniffing. Structural changes in the rural and industrial sectors, their impact on community functioning, and their association with elevated suicide have been in progress for some years. Social justice in education has yet to come to terms with emergent variant adolescent sexual orientation and various adolescent-onset mental health issues such as schizophrenia and depression.

School-based'psychological intervention is just beginning to focus strategies for prevention on combatting social anomie, strengthening personal resilience, and identifing critical support needs for highrisk groups and individuals. There is awareness, but action is concentrated at the point of attempted or completed sucide. Reduced access to guns may limit the accessibility of one method, but more creative and concerted community education effort will be needed to reduce the "acceptability" of other popular methods such as hanging (e.g., embargo on describing method in media reports).

\section{Feedback on larger font size}

Times 10 font used previously is enlarged in this issue to increase readability. It also increases costs, so positive feedback will affect future use.

\section{7 issues: Looking ahead and publishing on schedule}

The May 1997 Special Issue on motor coordination is based on the 1996 symposium at Perth ADHA conference. Brief manuscripts about other Australiasian work in this field not already represented should be submitted in December 1996 for consideration.

The November 1997 issue will feature innovative therapies and alternative perspectives on child therapy. Contents to date include solution-focused therapy, narrative therapy, psychoanalytic therapy, and suicide and psychoeducational therapy. Other manuscripts to that issue should be submitted by May 1997.

Fiona Bryer, Editor 